\title{
Detection of intervals / layers in sections of the wells with anomalous areas of drilling mud filtrate contamination according to the well logging (with negative test results of horizons)
}

\author{
Oleksiy Karpenko ${ }^{1, *}$, Vasyl Sobol ${ }^{2}$, Mykyta Myrontsov ${ }^{3}$, and Ivan Karpenko ${ }^{4}$ \\ ${ }^{1}$ Taras Shevchenko National University of Kyiv, Ukraine \\ ${ }^{2}$ State Commission of Ukraine on Mineral Resources, Kyiv, Ukraine \\ ${ }^{3}$ Institute of Telecommunications and Global Information Space of NAS of Ukraine, Kyiv, Ukraine \\ ${ }^{4}$ NJSC Naftogaz of Ukraine, Kyiv, Ukraine
}

\begin{abstract}
The zone of infiltration of the drilling fluid filtrate into the reservoir rock creates significant difficulties for the study by logging methods and during further testing of the formation. Due to the penetration of filtrate, significant contamination of the near-wellbore zone occurs. The porosity and filtration characteristics of reservoir rocks are changing. There is a possibility of blockage by filtrate in the invaded zone of oil or gas flow from the formation to the well. As a result of the studies carried out using well logging data, it was found that the presence and distribution of a mud cake on the borehole wall opposite the reservoir is an important factor influencing the process of filtration of the drilling fluid into the layers. On the examples of the Yablunivske oil and gas and Kolomatske gas fields of the Dnieper-Donets basin, it is shown that the absence of a mud cake on the borehole walls leads to the formation of maximum, anomalous zones of filtrate invasion. The determining of the diameter of the invaded zone was carried out according to the data of electrical logging methods. In addition, the diameter of the invaded zone was calculated as a solution direct task equation for the case of direct filtration without blocking by the mud cake. Comparison of the results of determining the diameter of the invaded zone by two methods made it possible to draw certain conclusions. An important conclusion is that even partial absence of mud cake on the reservoir wall in the well leads to horizontal and vertical filtration of the drilling fluid from the well into the formation. As a result, the invaded zone may be so deep, that the gas flow rate is absent even at high values of porosity, permeability and gas saturation.
\end{abstract}

\section{Introduction}

The process of drilling an oil and gas well inevitably causes the environmental contamination. Including geological. In addition to creating a hole in the wellbore in the permeable layers, a zone of invasion of the drilling fluid filtrate is formed. This filtrate is actually an aqueous solution of inorganic and organic compounds, significantly changing the geological environment around the well. The changes concern the porosity and permeability of reservoir rocks; there is a swelling of clay minerals, the well space is clogged with solid particles and colloids.

\section{Theory and Methods}

The main methods that allow to study the well outer space during and after drilling -the well logging. Actually, only with the help of the results of geophysical research it is possible to really estimate the size (diameter) of the invasion zone of infiltration of the filtrate into the porous layer. The principles of estimating the size of the filtrate invasion zone and its electrical characteristics were developed in the 50s of the last century [1]. Along with the development of sounding technology for electric logging systems of different sizes (BKZ), the interpretation of the logging data was proposed [1-3]. The wellbore space was considered as a 2-or 3-z medium. In the presence of filtrate penetration, it was considered that this invasion (penetration) zone (ZP) has different electrical characteristics than the formation and the well itself. The relative diameter of the invasion (penetration)zone Dzp/Cal was determined using the socalled 3-layer palettes BKZ. The most famous scientists, whose work was the basis for the interpretation of BKZ data, include the work of H.G. Doll, V.M. Dakhnov, S.G. Komarov, L.M. Alpin. Currently, the determination of the diameter of the invasion zone and its specific electrical resistivity is performed based on the results of studies of wells with multi-probe gradient probes, lateral logging, induction logging [4-7]. Thanks to the data of electrologging, researchers have the opportunity to assess and analyze the degree of filtration and the processes that occur during the formation of the invasion zone [8-10]. Here, geophysical methods are used as a tool to determine the parameters of the filtrate invasion zone in field research and interpretation of reservoir test results, features of primary reservoir opening, planning of optimal methods and perforation technologies [11-12].

\footnotetext{
*Corresponding author: karpenko.geol@gmail.com
} 
Calculations of the size of the invasion zone by solving the direct filtration task [13-18] indicate a wide range of approaches to take into account various factors that affect filtration processes in the gradient space around the well. Therefore, considerable attention should be paid to statistical modeling of the invasion zone based on the use of a priori information, which can be obtained from geophysical and other studies in drilled wells [19].

The total volume of permeable liquid leachate depends on the duration of time from the start of filtration, repression of pressure on the reservoir, the viscosity of the filtrate and formation fluid (and other rheological properties), the permeability of the reservoir [20,21] and the thickness of the mud cake [18, 22, 23].

The volume of filtrate that penetrated into the formation can be divided into two components. The first stage of penetration is the rapid absorption of the filtrate by the formation (instantaneous filtration). The second stage is the filtration of the washing liquid through the mud cake. However, even the inhibition of filtration into the formation by increasing the mud cake does not always contribute to the formation of small penetration zones. There are many examples of this, when under all the positive conditions regarding the reservoir characteristics of the formations, the presence of mud cake, the tests did not receive significant inflows of fluids into the wells [17, 24-26]. In addition, the technological parameters of drilling significantly influence the test result. According to the data [15-16], many wells drilled in Ukraine did not produce during development. These include the well № 100 - Kiltsivska Square, № 1 - Bitlyanska in the DnieperDonets Basin and several wells in the western region with very low reservoir pressures, namely: № 1 - Hutsulivska, № 3 - Kolomyia, № 6 - St. Bohorodchanska. All of them were drilled with excessive excess density of the drilling mud, respectively, huge invasion zones were formed. Only after changes in the drilling regulations by reducing the density of the flushing fluid from the standard used 1.20 to $1.10-1.20 \mathrm{~g} / \mathrm{cm}^{3}$ was obtained a conditional gas inflow.

Static and dynamic studies of the filtration properties of the washing liquid are used to estimate the filtration rates. To date, there is no universal model for calculating the parameters of the invasion zone, including its diameter.

If we do not take into account the influence of mud cake, then the first approximation, the depth of the penetration zone can be calculated by the following equation [16]:

$$
L=\frac{\Delta p \cdot \sqrt{K}}{a \cdot \tau_{0}}
$$

where $L$ is the radius of the invasion zone, m; $\Delta p$ - real repression of pressure on the formation, $\mathrm{Pa} ; K$ permeability coefficient of the rock, $\mathrm{m}^{2}[20,21]$; $a$-is the coefficient that can be taken [16] equal to $(155-180) \cdot 10^{-}$ 4; $\tau_{0}$-maximum / limit shear stress, Pa.

Thus, under normal conditions $(\Delta p=2 \cdot 106 \mathrm{~Pa} ; K=$ $\left.10 \cdot 10-15 \mathrm{~m}^{2} ; a=160 \cdot 10-4 ; \tau_{0}=10 \mathrm{~Pa}\right)$, the calculated value of penetration of the filtrate into the formation (in the absence of mud cake) is equal to $1.25 \mathrm{~m}$. This is a fairly significant value, which may already be the cause (or explanation) of the absence of inflow into the well of formation fluid or gas during testing.

Consider real examples of the absence of positive test results in comparison with the parameters of the layers and the invasion zone.

Well 14-Yablunivska (Fig.1). Testing of productive strata determined by the well-logging data was carried out according to the classical bottom-up scheme. In the interval of perforation by the corpus perforator PKOT-73 after 3 times aeration of salt water the inflow in the well was not obtained. Although the reservoir parameters of the reservoir (interval 5070-5071.6 m) are much higher than the limit: porosity $10 \%$, permeability coefficient 41.2 $\mathrm{mD}$ (by the well-logging), gas saturation $-83 \%$. The authors of the first report (1984) on the petroleum reserves calculation of Yablunivske field note that chalk was used as a weight addition during drilling; as a result, a large invasion zone with significantly deteriorated filtration properties was probably formed. This is the main explanation for the absence of fluid inflow from this reservoir. According to our calculations, the relative diameter Dzp/Cal here is 18.5 , and the absolute value of $\mathrm{Dzp}=3.7 \mathrm{~m}$.

Layers were also tested above the section in this well. In the range of 4921.6-5049.0 $\mathrm{m}$ (perforation by PKS-80) at the first lowering of the water level received a small inflow of gas with a flow rate of 1.5 thousand $\mathrm{m}^{3} / \mathrm{d}$. Only after 3 times of aeration the formation began to work with a gas flow rate of 49.2 thousand $\mathrm{m}^{3} / \mathrm{d}$. on an 8 -mm fitting. The weighted average parameters of reservoirs in the test interval: total layer thickness $48.7 \mathrm{~m}$, porosity $11 \%$, permeability coefficient $132.6 \mathrm{mD}$, gas saturation $84 \%$. According to our calculations, the relative diameter $\mathrm{Dzp} / \mathrm{Cal}$ here is 7.9 , and the absolute value of $\mathrm{Dzp}=1.5$ $\mathrm{m}$.

In the third interval $4876.8-4911.8$ of perforation by the corpus perforator PKS-89 after replacement of salt water with fresh water a significant inflow of gas was immediately obtained -284.8 thousand $\mathrm{m}^{3} / \mathrm{d}$. on an $8-\mathrm{mm}$ fitting. The reservoir properties of the formations are as follows: total layer thickness $10.5 \mathrm{~m}$, porosity $14.7 \%$, permeability coefficient $211 \mathrm{mD}$, gas saturation $85 \%$. The relative diameter Dzp/Cal here is equal to 5.1, and the absolute value of $\mathrm{Dzp}=1.1 \mathrm{~m}$. The given example of test results of terrigenous section layers of the Tournaisian stage in one well of Yablunivske oil and gas field testifies to the importance of taking into account not only the main reservoir parameters of formations (porosity, effective thickness and gas saturation), but also the permeability coefficient (penetration) [27, 28]. Inflow call technologies should be adjusted to take into account the size of the filtrate invasion zone with appropriate measures, including re-perforation.

In Fig. 1 shows the curve of the calculated values of the invasion zone depth (Lzp) according to the model (1) [16] of filtration into the formation in the case the absence of mud cake. The presence of mud cake makes significant adjustments to the size of the invasion zone. 


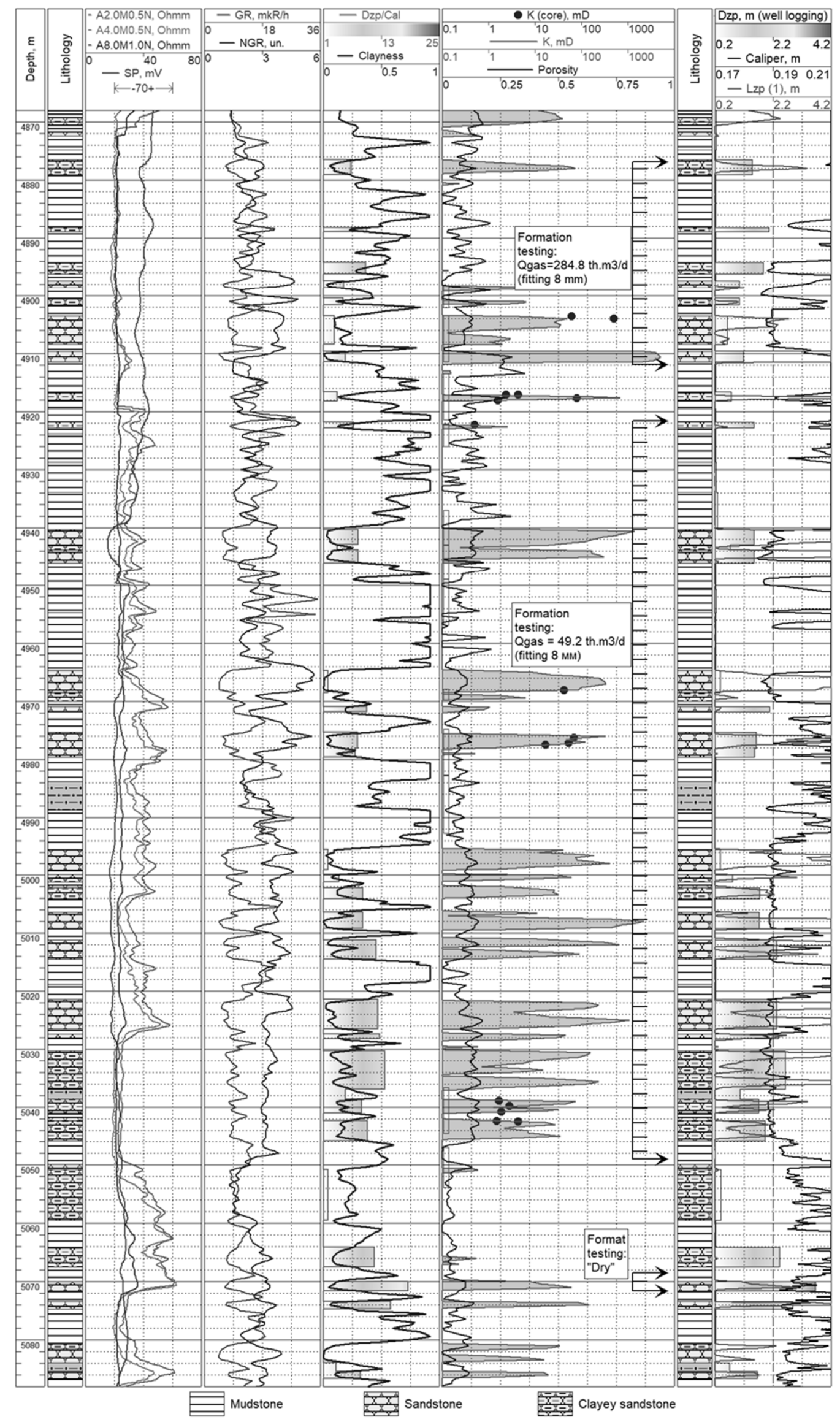

Fig. 1. Section of 14-Yablunivska well with the given test results and calculated values of the relative invasion zone according to welllogging data interpretation. 
The tendency is clearly visible: where is the mud cake (the diameter of the well is less than the diameter of the bit), the (in the main) the actual value of the diameter of the invasion zone is smaller than calculated without taking into account the effect of reducing the filtration through the mud cake. In the lower part of the section (Fig. 1), where the largest values of Dzp are observed, there is no mud cake at all. Due to the possible structural inhomogeneity of the rocks of the lower part of the Tournaisian stage, zones with increasing diameter were formed during drilling, in the absence of mud cake formation. As a result, there are large areas of filtrate penetration and negative results during the testing of formations (Fig. 2).

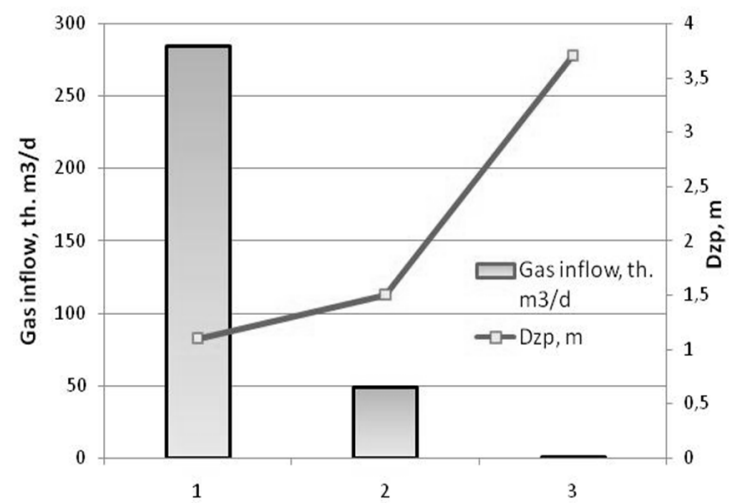

Fig.2. The ratio of the diameter of the invasion zone (according to well-logging data interpretation) and the obtained gas flow rate opposite the reservoirs of 14-Yablunivska well.

Similar negative test results due to the presence of a large zone of filtrate penetration in the sections of the wells, where there are gas-saturated reservoirs, were obtained in the significant number of Dnieper-Donets basin oil and gas fields. In Fig. 3 shows a tablet of log diagrams with the results of interpretation and test data of layers and perforation intervals of 31-Kolomatska well. It should be noted that the productive terrigenous strata of the Serpukhovian stage at the Kolomatske gas condensate field lie at considerable depths, more than $4500 \mathrm{~m}$. 31Kolomatska well show that a number of productive objects with porosity values higher than the critical 6.5 $10.5 \%$ are distinguished in the section. Gas saturation coefficient - in the range of $61-78 \%$.

During the testing of formations in the section interval 5486 - $5512 \mathrm{~m}$ inflow was not received. Perforation was performed using modern equipment OWEN 3 3/8 "with a frequency of 18 holes $/ \mathrm{m}$. According to the well-logging data, all layers of sandstone in this interval are productive (Fig. 3). Above in section according to the results of a joint test of two perforated intervals $5464-5475 \mathrm{~m}$ and 5440-5452 m received a conditional gas flow of 191.4 thousand $\mathrm{m}^{3} / \mathrm{d}$ on a $7-\mathrm{mm}$ fitting. The equipment and conditions of perforation here were similar.

Pays attention to the fact that in the lower test interval 5486 - $5512 \mathrm{~m}$ with negative results on the caliper curve there is almost no mud cake; the diameter of the well is larger than the diameter of the bit opposite the reservoirs. At the same time, in front of sandstones in the two upper perforation intervals 5464 - $5475 \mathrm{~m}$ and 5440-5452 m there is a mud cake everywhere (see curve Caliper in Fig. 3). Calculations of the values of the relative diameter of the invasion zone Dzp/Cal according to the electrical methods of well-logging using the GeoPoisk system [29] showed the following. In the test interval $5486-5512 \mathrm{~m}$, the values of Dzp/Cal in the reservoirs vary from 6.4 to 11.1 .

In the upper intervals, where a significant gas flow is obtained, the values of Dzp/Cal are generally at a minimum level of 2.0. Such values are observed in front of reservoir layers with porosity values greater than the limit values. Only in the range of 5470.5-5474.6 in the calculations obtained the value of the relative diameter of the invasion zone of 6.2 . We calculated the point values depth of the invasion zone of the filtrate $L$ by formula (1) [16]. These results correspond to the possible values of filter penetration in the absence of mud cake. In the lower interval in the negative test results in the actual absence of mud cake, the calculated values of the relative diameter $\mathrm{Dzp} / \mathrm{Cal}$ according to electrologging correlate well with the curve $L(L z p)$. That is, the fact of the presence of a large zone of filtrate penetration led to the absence of gas inflow to the well according to the test results (int. 5486 $5512 \mathrm{~m})$.

To verify the statement about the identity of reservoir rocks by their capacitive and productive properties in the intervals with different test results, statistical analysis was performed using Student's t-test. For this purpose, two multidimensional sample sets with the conditional names "gas" and "dry" were formed - according to the test results. Selection of parameter values was performed with a step of $0.5 \mathrm{~m}$ from $\log$ diagrams.

Table.1 gives a clear picture of the statistical characteristics (mean and standard deviation) of the main geophysical parameters and coefficients of clayness, porosity and gas saturation of the two objects (samples).

According to the table data, the limit value of the Student's t-test is equal to 1.99 by the value of the confidence interval $\alpha=0.05$. As you can see, only the mean (average) values of the diameter of the well, the intervals of the section have significant differences. Here, the value of the t-test 4.7 is significantly greater than the limit value of 1.99 (see Table 1) That is, the absence of mud cake (increasing the diameter on the Caliper curve) led to the formation of a large invasion zone in the sandstone interval with negative test results. Thus, there is reason to believe that the results of the preliminary conclusion about the presence of a gas-saturated reservoir within the test interval 5486 - $5512 \mathrm{~m}$ are statistically confirmed. And the test results in this interval should be considered unproven. 


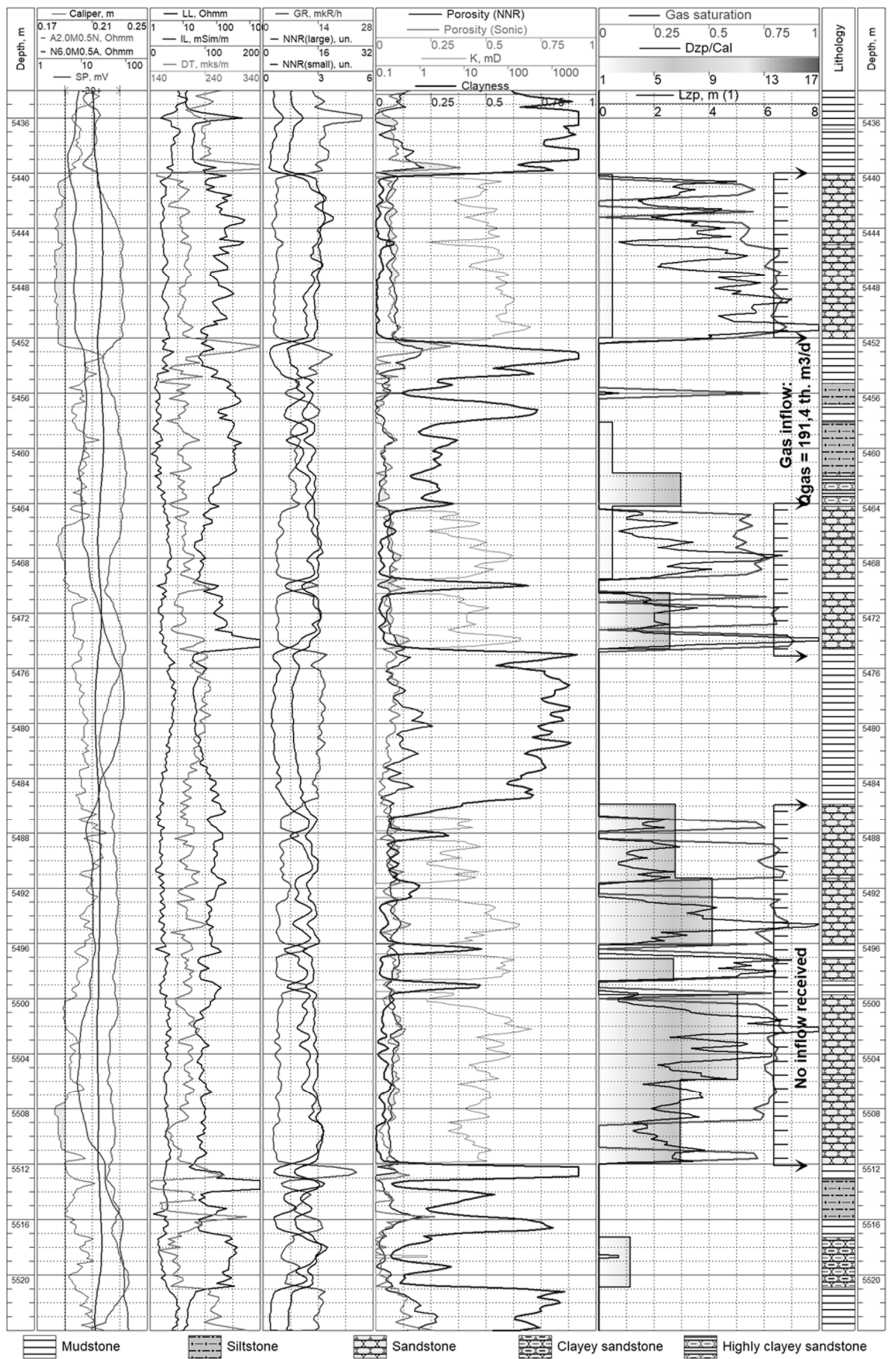

Fig. 3. Section of 31-Kolomatska well with test results and calculated values of the relative penetration zone depth according to welllogging data interpretation. 
Table 1. Statistical characteristics of the distributions of petrophysical characteristics of sandstones for two test intervals: int. 5440 5475 (conditional gas inflow), int. 5486 - 5512 (inflow not received). Well 31-Kolomatska.

\begin{tabular}{|c|c|c|c|c|c|c|c|c|}
\hline $\begin{array}{l}\text { Result of } \\
\text { formation } \\
\text { testing }\end{array}$ & $\mathrm{N}$ & $\begin{array}{c}\mathrm{DT}, \\
\mathrm{mks} / \mathrm{m}\end{array}$ & Caliper, $\mathrm{m}$ & $\begin{array}{c}\mathrm{GR}, \\
\mathrm{mks} / \mathrm{m}\end{array}$ & Clay & $\begin{array}{c}\text { Resistivity, } \\
\mathrm{ohm} \cdot \mathrm{m}\end{array}$ & Porosity & $\begin{array}{l}\text { Gas } \\
\text { saturation }\end{array}$ \\
\hline \multicolumn{9}{|c|}{ Means } \\
\hline Gas inflow & 45 & 201.1 & 0.196 & 3.71 & 0.063 & 105.0 & 0.072 & 0.629 \\
\hline Dry & 44 & 205.0 & 0.207 & 3.91 & 0.069 & 90.2 & 0.083 & 0.678 \\
\hline \multicolumn{9}{|c|}{ Standard deviations } \\
\hline Gas inflow & 45 & 11.5 & 0.010 & 1.15 & 0.053 & 59.2 & 0.017 & 0.283 \\
\hline Dry & 44 & 14.6 & 0.013 & 0.68 & 0.026 & 13.7 & 0.021 & 0.275 \\
\hline \multicolumn{9}{|c|}{ Calculated t-test values (cut off value 1.99) } \\
\hline $\begin{array}{l}\text { t-test } \\
\text { values }\end{array}$ & $\begin{array}{c}44+ \\
45\end{array}$ & 1.39 & $\underline{4.70}$ & 1.02 & 0.68 & 1.64 & 2.74 & 0.82 \\
\hline
\end{tabular}

\section{Conclusions}

The process of drilling mud penetration into the reservoirs and the formation of the invasion zone can be divided into three main stages. In the first stage, when drilling near the bottom of the well in the area of the most active circulation of the flushing fluid, there is an area of high pressure with a large pressure drop not only in the radial direction, but also along the axis of the well. In the second stage, an important factor in the formation of the invasion zone is the formation of a mud cake on the wall of the well, which significantly impedes the water exchange processes between the well and the layers [30]. In the initial moments of time there is a squeezing of formation water and oil / gas phase from the bottom hole, which has a spatial character. In the third stage, after the drilling tool leaves the reservoir, the displacement process is mainly due to the excess of the constant hydrodynamic pressure in the well above the reservoir pressure and is mainly radial [30].

Our research using the methods of mathematical statistics proved that for terrigenous reservoir rocks with a granular type of porosity on the examples of several oil and gas condensate and gas condensate fields the following was established.

1. Negative test results of formations (with the recommended oil and gas potential according to the welllogging data) in the perforation intervals are caused by the presence of anomalous zones of penetration of the flushing fluid filtrate [24, 31]. Among other factors of different nature, the depth of the invasion (penetration) zone (Dzp) is largely controlled by the presence and size of the mud cake. The presence of a mud cake leads to "containment" or "inhibition" of the filtration of the liquid into the formation, resulting in the formation of small invasion zones. It is recommended to compare the calculated values of the penetration depth of the filtrate $L$ $(L z p)$ in the absence of mud cake (1) with the values of the diameter of the penetration zone Dzp according to the electrical methods of well-logging. Similar in size, the large areas of the filtrate invasion by two calculations are evidence of a problematic situation and a high probability of no fluid inflow from the formation during the test. The use of calculations in two ways significantly increases the reliability of the conclusions about the flow of the invasion zone on the test results.

2. It is proved that the presence of a mud cake along the entire thickness of the productive layer significantly affects the formation of small zones of penetration of the filtrate and contributes to obtaining reliable test results within the perforation interval. If the mud cake is only partially formed within the formation crossing by the well, then there is a high probability that the filtrate penetration can occur not only in the radial but also in the vertical directions in the formation, which can cause large diameters of the invasion zone Dzp.

\section{References}

1. L.M. Alpin, BKZ lateral logging pallets. M. Gostoptekhizdat (1958)

2. V.N. Dakhnov, Electric and magnetic methods of well survey. M. Nedra (1981)

3. S.G. Komarov, Geophysical well survey methods. M. Nedra (1973)

4. M.I. Epov, Yu.N. Antonov, Oil and gas well survey technology based on VIKIZ. Methodical guidance. Novosibirsk. SIC JIHGM SB RAS. Publishing house of the SB RAS (2000)

5. B.I. Anderson, Modeling and inversion methods for the interpretation of resistivity logging tool response. Paris. Schlumbergerprint (2001)

6. M.L. Myrontsov, The problem of equivalence in inverse electrometry problems of oil and gas wells. 18th International Conference "Geoinformatics - Theoretical and Applied Aspects", Extended Abstracts (2019)

7. M.L. Myrontsov, O.M. Karpenko, O.M. Trofymchuk, V.O. Okhariev, Examples of determination of spatial and geoelectric parameters of productive beds of deposits of the Dnipro-Donetsk depth. XIV International Scientific Conference "Monitoring of Geological Processes and Ecological Condition of the Environment", Extended Abstracts (2020)

8. D. Longeron, A. Argillier, J.F. Audibert, An integrated experimental approach for evaluating formation damage due to drilling and completion fluids. European formation damage control conference (1995) 
9. K.L. Fedin, Experimental studies of the formation of a zone of penetration in oil and gas reservoirs and ways to increase the efficiency of well logging: On the example of the Timano-Pechora oil and gas province. Ph.D. Thesis. M (2001)

10. V.A. Irbe, Study of reservoirs at different distances from the borehole wall with waters of unequal mineralization, determined in the laboratory and according to well logging data. Bulletin of the subsoil user of the Khanty-Mansiysk Autonomous Okrug. 22 (2011)

11. R.M. Kondrat, L.I. Khaidarova, Research of influence of characteristics of opening of gas-bearing layers by perforation on production possibilities of a well. Exploration and development of oil and gas fields. № 4 (73) (2019)

12. Yu.D. Kachmar, V.M. Svitlitsky, B.B. Sinyuk, R.S. Yaremiychuk, Intersification of hydrocarbon inflow into the well. Book one. Lviv. Center of Europe (2004)

13. A. Abrams, Mud design to minimize rock impairment due to particle invasion. Journal of Petroleum Technology. № 29 (1977)

14. Kegang Ling, He Zhang, Zheng Shen, Ali Ghalambor et al., A new approach to estimate invasion radius of water-based drilling fluid filtrate to evaluate formation damage caused by overbalanced drilling. SPE Drilling \& Completion Publisher: Society of Petroleum Engineers (2015)

15. R.R. Ishbaev, Y.V. Zeigman, Diagnosis of the influence of the technologies of primary opening and tamponing of wells on the filtration parameters of the rocks of the bottom hole zone of the formation. Oil and gas business. №3 (2012)

16. Sh.K. Gimatudinov, Reference book on oil production. M. Nedra (1974)

17. A.A. Kashevarov, I.N., Eltsov, M.I., Epov, A hydrodynamic model of the formation of an invasion zone during well drilling, Prikl. mechanics and tech. physics. 44, No. 6 (2003)

18. S.N. Gadzhiev, I.V. Popov, The use of colmatation to prevent complications during well construction. Construction of oil and gas wells onshore and offshore. No. 12 (2008)

19. A.Y. Gunawan, P. Sukarno, E. Soewono, Modeling of Mud Filtrate Invasion and Damaged Zone Formation. Journal of Petroleum Science and Engineering, 77(3) (2011)

20. O. Karpenko, M. Myrontsov, I. Karpenko, V. Sobol, Detection conditions of gas-saturated layers by the result of complex interpretation of non-electrical well logging data. Monitoring 2020 Conference "Monitoring of Geological Processes and Ecological Condition of the Environment", Extended Abstracts, Kyiv (2020)

21. A. Timur, An Investigation of Permeability, Porosity, and Residual Water Saturation Relationship for Sandstone Reservoirs. The Log Analyst, 9 (1968)
22. G.R. Coats, J.L. Dumanoir, A New Approach to Improved Log-Derived Permeability. The Log Analyst. January - February, 17 (1974)

23. V.Kh. Akhiyarov, Features of the formation of the invaded zone and its influence on the characteristics of reservoirs in the terrigenous section of the West Siberian Plain. Tyumen. Proceedings of ZapSibNIGNI. 106 (1975)

24. C. P. Ezeakacha, S. Salehi, A. Hayatdavoudi, Experimental Study of Drilling Fluid's Filtration and Mud Cake Evolution in Sandstone Formations. J. Energy Resour. Technol. 139(2). Mar. (2017)

25. O.O. Ivankiv, V.M. Svitlitsky, M.M. Yavorsky, A.A. Pisarenko, New methods of opening and development of formations with abnormally low formation, pressures (ANPT). Scientific Bulletin IFNTUNG. № 2 (16) (2007)

26. S. Vickers, M. Cowie, T. Jones, B. A. Hughes, New methodology that surpasses current bridging theories to efficiently seal a varied pore throat distribution as found in natural reservoir formations. Wiertnictwo nafta gaz. Tom 23/1 (2006)

27. E.A. Orlov, V.I. Nikitin, P.V. Dykin, Preservation of the reservoir properties of the reservoir by introducing clogging additives into the drilling fluid. Modern technologies for personnel training and advanced training of oil and gas production specialists (2017)

28. V.A., Starostin, R.I. Nagornyak, Filtration model of oil and gas fields as a control criterion for detecting missed productive intervals. Exploration and development of oil and gas fields. 1 (50) (2014)

29. M.D. Krasnozhon, V.D. Kosachenko, V.G. Tulchinsky, P.G. Tulchinsky, Development of the Geopoisk technology for studying oil and gas and ore deposits. Karotazhnik. 2 (155) (2007)

30. V.I. Nikitin, V.V. Zhivaeva, Dynamics of penetration of filtrate of water-based drilling flushing systems into the formation. Construction of oil and gas wells on land and at sea. №11 (2017)

31. V.S. Boyko, Development and operation of oil fields. Kyiv. Real-Print (2004) 